
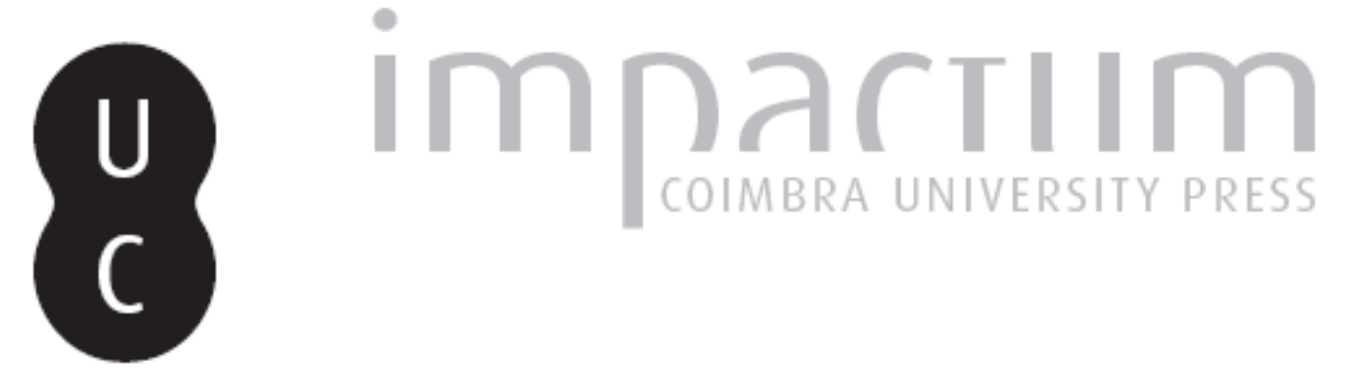

\title{
O ensino superior politécnico em portugal: presente e futuro
}
Autor(es): $\quad$ Mourato, Joaquim António Belchior
Publicado por: Fórum de Gestão do Ensino Superior nos Países e Regiões de Língua Portuguesa

URL

persistente:

URl:http://hdl.handle.net/10316.2/36222

DOI:

DOI:http://dx.doi.org/10.14195/2183-2722_1-1_5

Accessed : $\quad$ 26-Apr-2023 15:32:28

A navegação consulta e descarregamento dos títulos inseridos nas Bibliotecas Digitais UC Digitalis, UC Pombalina e UC Impactum, pressupõem a aceitação plena e sem reservas dos Termos e Condições de Uso destas Bibliotecas Digitais, disponíveis em https://digitalis.uc.pt/pt-pt/termos.

Conforme exposto nos referidos Termos e Condições de Uso, o descarregamento de títulos de acesso restrito requer uma licença válida de autorização devendo o utilizador aceder ao(s) documento(s) a partir de um endereço de IP da instituição detentora da supramencionada licença.

Ao utilizador é apenas permitido o descarregamento para uso pessoal, pelo que o emprego do(s) título(s) descarregado(s) para outro fim, designadamente comercial, carece de autorização do respetivo autor ou editor da obra.

Na medida em que todas as obras da UC Digitalis se encontram protegidas pelo Código do Direito de Autor e Direitos Conexos e demais legislação aplicável, toda a cópia, parcial ou total, deste documento, nos casos em que é legalmente admitida, deverá conter ou fazer-se acompanhar por este aviso.

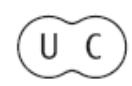




\section{REVISTA}
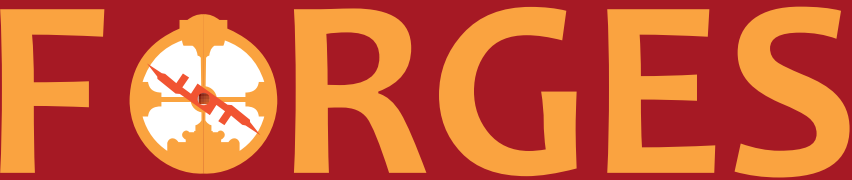

Fórum da Gestão do Ensino Superior nos Países e Regiões de Língua Portuguesa

Ensino Superior

Organizadores

Sônia Fonseca | Luísa Cerdeira |

Tomás Patrocínio
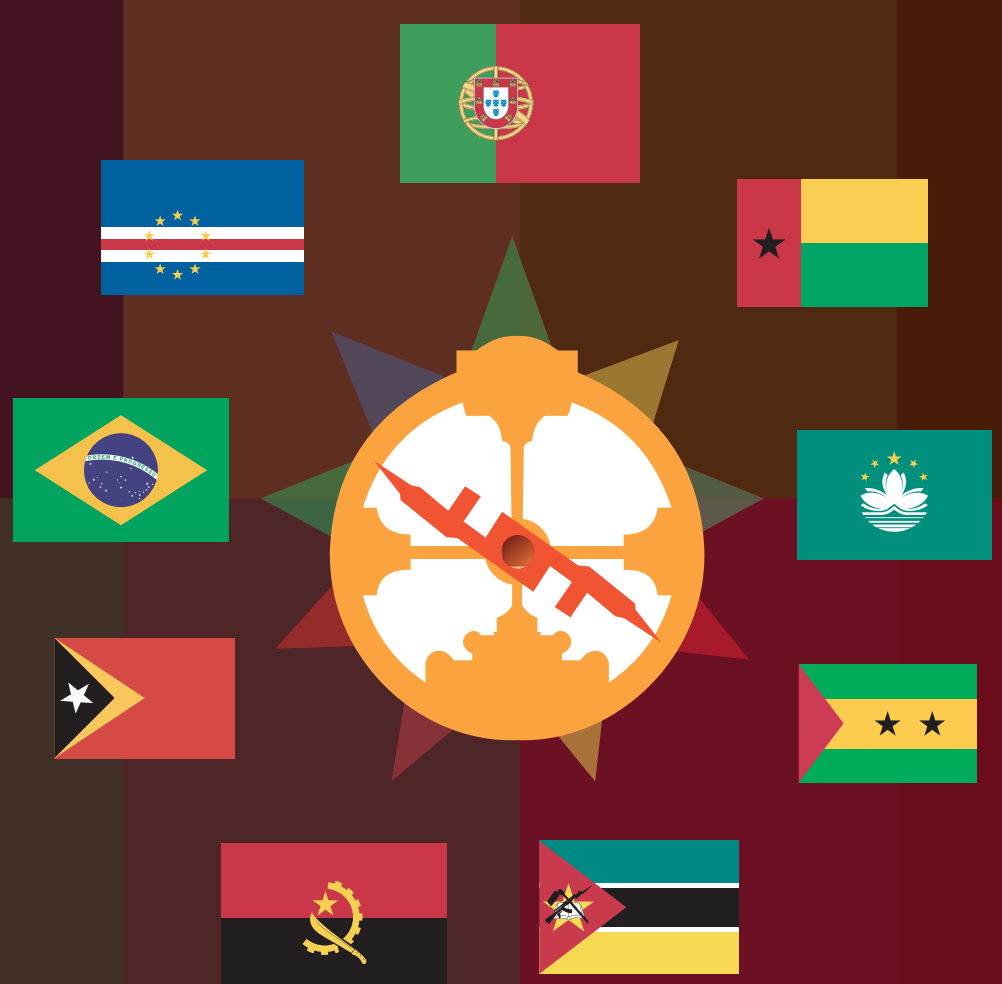


\title{
5
}

\section{O ensino superior politécnico em portugal - presente e futuro}

\author{
Joaquim António Belchior Mourato ${ }^{1}$
}

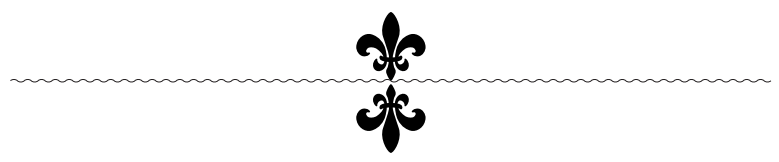

\begin{abstract}
The richness and well-being of countries, organisations and individuals have been founded on the creation, dissemination and use of knowledge. Therefore, there are moments in the life of peoples and societies, where sharing a common enlarged civic feeling leads to the consensus over the imperative to act with courage and determination on an emergent need, namely: What are the needs of higher education in Portugal? In what way can higher education contribute so that Portugal may face the challenges for the next decades?

An usual conclusion is that gobal reordering is considered as a priority. The time signs point to an interplay of favourable conditions to this quality leap, namely a huge contextual change, an international opportunity and the insatisfaction among meaningful segments of society.

The timely initiative of promoting a discussion about the condition of the Portuguese higher education remains a central issue in a debate that is still lively and should lead us to a calm yet courageous reflection on the matter. The redefinition of the university and polytechnic sub-systems is urgent, with well distinct competencies translated to practice.

Currently decades of academic governance are under discussion. Hence the need to name the main proposals for the future of the Portuguese polytechnic higher education, on the path to its construction and in accordance with a strategic vision aiming at a thorough and rigorous reform.
\end{abstract}

1 Presidente do CCISPe do Instituto Politécnico de Portalegre. 


\section{Introdução}

Uma das temáticas mais comuns na sociedade portuguesaenquadra-se, precisamente, na reforma do ensino superior. É presença obrigatória em todos os programas de governo da última década eintegra os discursos dos dirigentes das instituições de ensino superior, das associações estudantis, bem como de académicos e pensadores. Portanto, não é de estranhar o aumento de teses académicas e publicações nesta área (Mourato, 2013a).

Frequentemente afirma-se que a História é mestra da vida. Atualmente existe o reconhecimento geral de se ter chegado a uma situação de crise, sendo necessárias profundas reformas. Basta recordar um passado recente e será possível reunir temas e experiências que,melhor,contribuirão para a compreensão do presente, permitindo a recolha de dadospara a construção do futuro (Amorim, 2004).

Como é sabido, a configuração do sistema de ensino superior em Portugal apresenta-se sob a formade sistema binário, na qual coexistem o subsistema de ensino universitário e o subsistema de ensino politécnico (CCISP, 2006). De realçar que, nas últimas décadas a sua evolução pode ser genericamente retratada como uma história de sucesso, pese embora alguns insucessos. A louvar, desde logo, a massificação do ensino superior. Este fenómeno traduziu-se num dos maiores acontecimentos políticos do país, seja qual for o setor considerado (CCISP, 2003). No entanto é de realçar que ocorreu com cerca de 20 anos de atraso, comparativamente aos demais países da União Europeia.Por outro lado, ressalta uma lacuna que permanece incompreensível designadamente a inexistência de uma rede de dados atualizada ao nível dos indicadores científicos, académicos, financeiros e de impacto social das instituições de ensino superior. A génese para esta mudança será o enraizamento da diversidade e a sua clara definição institucional. Há quedefinir claramente, para os dois subsistemas: objetivos; financiamento; autonomia;comunidade; organização e a relação transparente com o tecido empresarial, partindo-se de uma igual dignificação social (FNAEESP², 2003).

Continuando, em resultado de uma breve análise, mesmo que superficial, à evolução da legislação de 1901 a 1974 constata-se que

2 Federação Nacional das Associações de Estudantes do Ensino Superior Politécnico 
muitos dos problemas atuais já o eram no passado, embora tenham emergido de ambientes políticos, culturais e sociais distintos (Simão, 2003). Com o 25 de abril de 1974 ocorreu um processo de democratização crescente do ensino superior, do aumento da investigação académica e uma forte expansão da rede. No entanto, Portugal confronta-se, agora, com uma nova realidade e com os desafios impostos pelo Espaço Europeu de Ensino Superior. Mais do que nunca é tida como cabal uma reflexão sobre o presente e o futuro do ensino superior português, sobretudo no que diz respeito à dinâmica das instituições públicas de ensino superior e em que medida é que esta se apresentacomo apropriada para responder às questões do desenvolvimento socioeconómico em Portugal (Mourato, 2013a).

Também, a credibilidade de graus e diplomas tem sido fortemente questionada pela opinião pública.A maior incidência da avaliação incidiu, inicialmente, na avaliação de cursos. No entanto, atendendo ao desenvolvimento da avaliação ao nível europeu o processo da avaliação deve compreender a avaliação institucional, a avaliação dos cursos e a avaliação de unidades orgânicas (Simão, 2003).

Igualmente se afirma que em Portugal se tem assistido a um movimento de aproximação dos dois subsistemas, pondo-se em causa a estrutura dual existente (Almeida, 2011; Diogo, 2009). No entanto,o subsistema politécnico é vital para as necessidades do mercado de trabalho, o qual ansiosamente tem alocado os técnicos formados pelas instituições politécnicas com referência à sua competência, valor e saber fazer (FNAEESP, 2003).

Comparativamente a outros países da $\mathrm{OCDE}^{3}$, paraque Portugal supere o atraso ao nível da sua educação superior colocam-se várias questões (OCDE, 2006). Porventura o processo de reorganização da rede de estabelecimentos de ensino superior poderá não passar pela extinção ou redução de instituições. No entanto, é desejável o aumento da cooperação entre estas.Há que redefinir a sua missão e oferta formativa para que se alcance um papel de relevo na formação de quadros superiores de excelência, competentes e promotores do desenvolvimento do País, da Europa e do Mundo. O fenómeno da reordenação da rede de instituições, para o subsistema politécnico,deve assumir-se enquanto pilar essencial

3 Organização para a Cooperação e Desenvolvimento Económico 
para a sustentabilidade da educação, da economia, do estado social, e do País (Mourato, 2013a).

Antes de dar início à análise prospetiva, há que determinar, inicialmente, de quecarece a sociedade portuguesa para que o seu desenvolvimento económico, social e cultural seja uma realidade, tal como os vários desafios, económicos, sociais e culturais, que serão colocados ao país e que terão que ser ultrapassados para bem da nação e do nosso Estado Social (CCISP, 2013a).

\section{Um olhar sobre a Europa}

Existem, a nível mundial, uma multiplicidade de estruturas caraterísticas dos inúmeros sistemas de ensino superior. Desde logo, é possível distinguir dois grandes modelos/estruturas de ensino superior (Kirstein, 1999), designadamente sistemas unitários (e.g EUA)e sistemas binários (e.g Alemanha).Assim, em diversos países, o modelo binário de ensino superior traduz-se na existência de dois setores de ensino superior diferenciados onde coexistem por um lado, as universidades tradicionais, as quais ministram formações mais teóricas e orientadas para a investigação e, por outro, outras instituições de ensino superior, responsáveis pela oferta de cursos superiores de índole profissionalizante (Harvey, 2004-13; Kirstein, 1999).

De realçar que, o sistema binário é o modelo de ensino superior mais comum na Europa (Costa, 2002; Urbano, 2011). A semelhança entre a estrutura que encontramos ao nível do ensino superior em diversos países europeus "leva a pensar num fenómeno de globalização da institucionalização de um sistema binário no quadro europeu de formação superior" (Urbano, 2011, p.96).

\section{As instituições de ensino politécnico no contexto europeu}

O estabelecimento das instituições politécnicas teve um ponto de partida comum na maior parte dos países. De acordo com Haug e Tauch (2001) e com Kirstein (1999), podem sintetizar-se os seus objetivos a: 
- Uma resposta eficiente às necessidades do mercado de trabalho, com a oferta de um ensino mais prático e vocacional, sendo economicamente relevante.

- Alocar um número crescente de candidatos ao ensino superior sem aumento substancial da despesa do governo com este setor.

- Atingir de uma forma inovadora grupos de estudantes não convencionais.

- Oferecer programas de estudo primeiramente orientados para a aprendizagem, mas contendo uma componente de investigação aplicada.

- Dar continuidade ao ensino profissional pós-secundário.

Apesar das instituições de ensino superior politécnico serem tão comuns na Europa, nunca existiu consenso relativamente à designação a ser-lhes atribuída (Teichler, 2008).

A Tabela 1 demonstra a diversidade de designações existentes para este tipo de instituições em diversos países da Europa. 


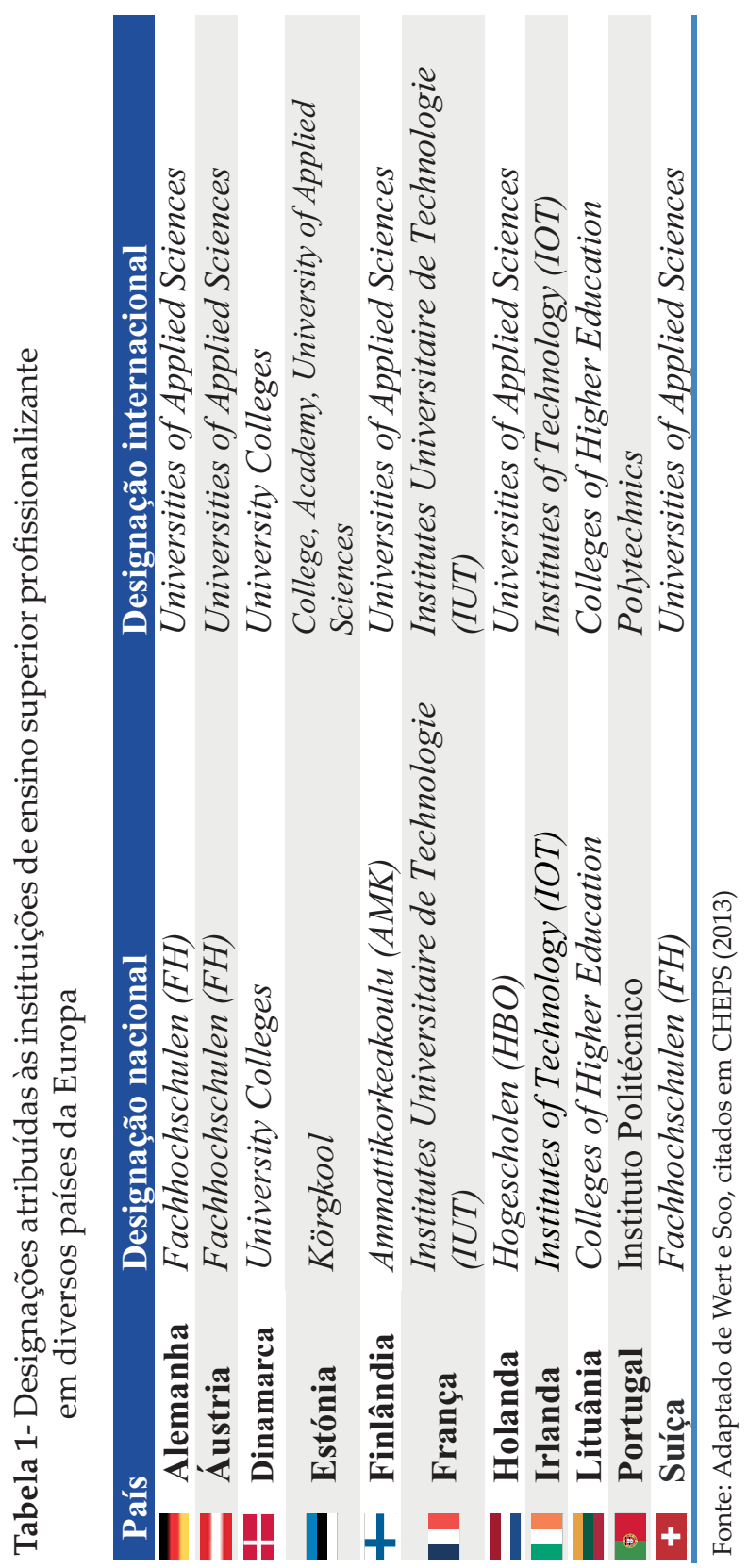

Revista FORGES - Fórum da Gestão do Ensino Superior 


\subsection{Tendências no seio europeu}

Embora o sistema binário seja um lugar-comum na Europa, muito se comenta o fenómeno deaproximação entre os dois subsistemas, ou o dissipar das diferenças existentes entre ambos (Kirstein, 1999; Comissão Europeia, 2012). Kirstein, em 1999, explicitava que este fenómeno resultava não só do crescente empenho das universidades em abranger atividades mais orientadas para a prática como também do crescente desenvolvimento académico observado pelo subsistema politécnico. A ADISPOR ${ }^{4}$ também,realizou um estudo contemplando 16 comunidades do Espaço Europeu de Ensino Superior (EEES) ${ }^{5}$, cujas conclusões são coincidentes, a saber (ADISPOR, 2102):

- Na generalidade dos países em análise não existe uma restrição legal ao nível das áreas de estudo a serem ministradas por cada um subsistemas, mas apenas uma diferenciação no cariz da formação ministrada (mais teórica nas universidades e mais prática nas instituições politécnicas).

- Em todos os países, as universidades tradicionais ministram formações que podem ser consideradas de cariz politécnico.

- Em consequência das exigências do mercado de trabalho, há países em que os planos de estudo das universidades tradicionais tendem a tornar-se mais práticos.

- Em alguns países as instituições politécnicas podem ministrar, além do segundo ciclo de estudos, também o terceiro ciclo.

Nesta rota, com referência ao estudo desenvolvido em 2013 pelo prestigiado Centro de Estudos de Políticas de Ensino Superior (CHEPS) da Universidade de Twente (Holanda), é possível, ainda,

4 Associação dos Institutos Superiores Politécnicos Portugueses.

5 Alemanha, Áustria, Bélgica - Comunidades de língua alemã, flamenca e francesa, Espanha, Estónia, Dinamarca, Finlândia, França, Irlanda, Lituânia, Noruega, Portugal, Suécia e Suíça. 
acrescentar que em diversos países o subsistema politécnico enfrenta atualmente uma série de desafios políticos que são comuns às diversas nações e os quais se traduzem numa diversidade de tendências europeias em termos de políticas educativas, das quais se destacam (CHEPS, 2013):

- Gradual uso do termo universidades de ciências aplicadas, para a designação internacional das instituições politécnicas (Tabela 1)

- Uma maior cooperação entre instituições de ensino superior, através de consórcios,fomentando e desenvolvendo o subsistema politécnico, onde se destaca também a cooperação intersectorial (entre o subsistema politécnico e o universitário).

- Necessidade de demarcação do subsistema politécnico através de uma oferta formativa de natureza marcadamente profissionalizante de maior amplitude, que englobe cursos desde o nível de ensino superior de curta duração até ao nível de doutoramento.

- Redução do número de programas de primeiro ciclo considerados redundantes, sobretudo em países com baixa densidade populacional.

- Entendimento geral acerca da necessidade de implementar medidas que assegurem a sustentabilidade do ensino politécnico, através de um maior equilíbrio de participação dos estudantes nos dois subsistemas, à semelhança dos casos de sucesso da Alemanha e Noruega.

- Maior foco das instituições politécnicas nas atividades de investigação, sobretudo no que se refere à investigação aplicada em cooperação, não só com as pequenas e médias empresas (PME) locais, mas também com o setor universitário.

- Reforço das atividades de internacionalização das instituições de ensino superior, sobretudo no que se refere ao recrutamento de estudantes a nível internacional. A internacionalização do staff das instituições e das suas atividades de investigação são aspetos que têm vindo também a ganhar importância. 


\subsection{Ensino politécnico em Portugal e na Europa: perspetiva comparada}

São várias as semelhanças que o sistema politécnico português apresenta comparativamente aos subsistemas homólogos de outras comunidades do EEES. Com referência ao estudo do CHEPS é possível destacar o seguinte (File, 2013):

- As instituições de ensino politécnico em Portugal apresentam, em média, uma dimensão semelhante às instituições homólogas de outras quatro comunidades (Holanda, Dinamarca, Noruega e Finlândia).

- A diversidade programática (relativamente às áreas de estudo ministradas) nas instituições politécnicas portuguesas é semelhante à encontrada na Holanda, Noruega e Filândia, mas maior do que a que é observada na Dinamarca, Estónia e Suécia, países onde as instituições tendem a ser mais especializadas.

- A diversidade programática (no que se refere ao nível de qualificações) das instituições politécnicas portuguesas é semelhante à de outros países (verificando-se a predominância de cursos de $1^{\underline{0}}$ ciclo e de curta duração), observando-se que muitas comunidades estão a apostar nos mestrados. Refirase ainda que em países como a Irlanda e a Noruega as instituições politécnicas também ministram doutoramentos.

- A atividade de investigação nas instituições politécnicas portuguesas, em termos do seu peso na despesa, é semelhante à de outros países mas menor que a de comunidades como a Noruega, Finlândia e Suécia, onde a missão de investigação das instituições (assim como o respetivo financiamento) é mais forte. 


\section{$4 \mathrm{O}$ ensino superior politécnico português}

Após a Revolução de Abril de 1974 o ensino superior foi extensível ao setor privado ${ }^{6}$ e assistiu-se à criação do sistema binário de ensino (Cardoso et al., 2011). Instituído em 1977,o ensino superior de curta duração objetivava ministrar uma formação técnica de nível superior (Simão, Santos, \& Costa, 2002).Em 1979 passa a designar-se de ensino politécnico, coexistindo com o ensino universitário. Desde então, verificou-se uma relevante diversificação e expansão da rede de estabelecimentos (A3ES $\left.{ }^{7}, 2012\right)$.

Oensino politécnico em Portugal em muito contribuiu para "colmatar a escassa democratização e a falta de diversificação do ensino superior existente até então" (Urbano, 2011, p.100). Até essa data o ensino superior em Portugal era integrado apenas pelo setor universitário. Logo, não detinha orientação profissional que lhe permitisse ministrar programas de formação destinados a nichos específicos do mercado de trabalho (Diogo, 2009). E tal como em muitos outros países europeus, uma das intenções subjacentes àfundação do ensino politécnico era também, a promoção do desenvolvimento regional e das relações com as atividades económicas e sociais, propósito que se mantém válido até aos dias de hoje (Costa, 2002; Diogo, 2009).

O Sistema binário do ensino superior em Portugal tem várias implicações, nomeadamente (CCISP, 2006):

- A natureza do ensino ministrado pelas instituições - mais conceptual nas universidades, mais teóricoprático nos institutos politécnicos.

- A diferente competência para conferir graus académicos - as universidades podem conferir o grau de licenciado, mestre e doutor,os politécnicos o grau de licenciado e o de mestre.

- A natureza da investigação - fundamental e aplicada nas universidades e aplicada nos politécnicos.

\footnotetext{
6 Apesar de em 1971 ter sido já criada a primeira universidade não dependente do Estado em Portugal, através do reconhecimento da Universidade Católica Portuguesa (criada em 1940), enquanto tal (Almeida, 2011).

7 Agência de Avaliação e Acreditação do Ensino Superior.
} 
Apesar da distinção formal existente entre os dois subsistemas (Figura 1), o certo é que, à semelhança do que acontece a nível europeu, em muito devido ao Processo de Bolonha, também em Portugal se tem assistido a um movimento de aproximação do subsistema universitário e politécnico, o qual vem pôr em causa a estrutura dual existente (Almeida, 2011; Diogo, 2009). No entanto, a tendência parece apontar para a manutenção e até reforço do modelo binário (Diogo, 2009).

Figura 1 - Distinção dos subsistemas de ensino superior, de acordo com os textos legislativos

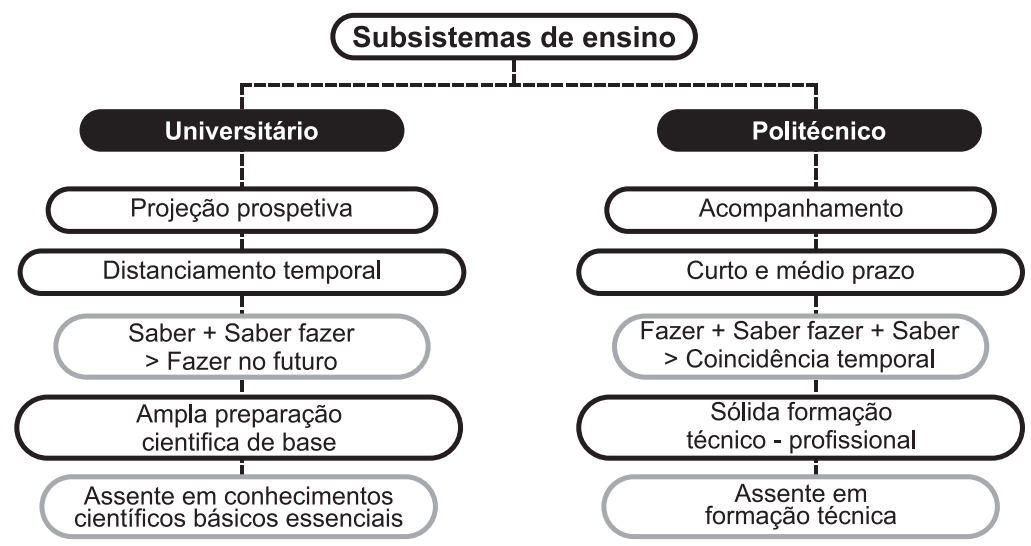

Fonte: Adaptado de Urbano (2008)

\subsection{A rede pública do ensino superior}

Na evolução da rede pública de ensino superior, destacam-se fundamentalmente duas épocas, nomeadamente: o período que se seguiu à implantação da República e o período entre 1972 e 1980. Estes marcaram o reequacionar da rede (Lourtie, 2013).

A rede de ensino superior portuguesa engloba 121 instituições, correspondentes a 338 unidades orgânicas, as quais se encontram distribuídas pelos subsistemas universitário e politécnico (de natureza pública ou particular). No entanto, é de realçar que o ensino superior público agrega cerca de um terço das instituições e quase 
60\% das unidades orgânicas (A3ES, 2012).

A rede de estabelecimentos de ensino superior universitário público é constituída por 14 universidades e 1 instituto universitário não integrado. A estes estabelecimentos acrescem 4 instituições universitárias de ciências militares e policiais (DGES', 2011/12).

Em Portugal o ensino politécnico é ministrado em institutos politécnicos, em escolas politécnicas não integradas e em escolas politécnicas integradas em universidades. A rede pública de ensino politécnico é constituída por 15 institutos politécnicos, 5 escolas superiores não integradas, 2 instituições de ensino militar e policial e pelos estabelecimentos politécnicos de 7 universidades (Açores, Algarve, Aveiro, Évora, Minho, Trás-os-Montes e Alto Douro e Madeira) (DGES, 2011/12).

Assim é assegurada uma melhor cobertura geográfica do território nacional, comparativamente à do ensino universitário, sobretudo no que se refere ao interior do país (Costa, 2002) (Figura 2).

8 Direção Geral do Ensino Superior. 
Figura 2 - Rede de ensino superior público
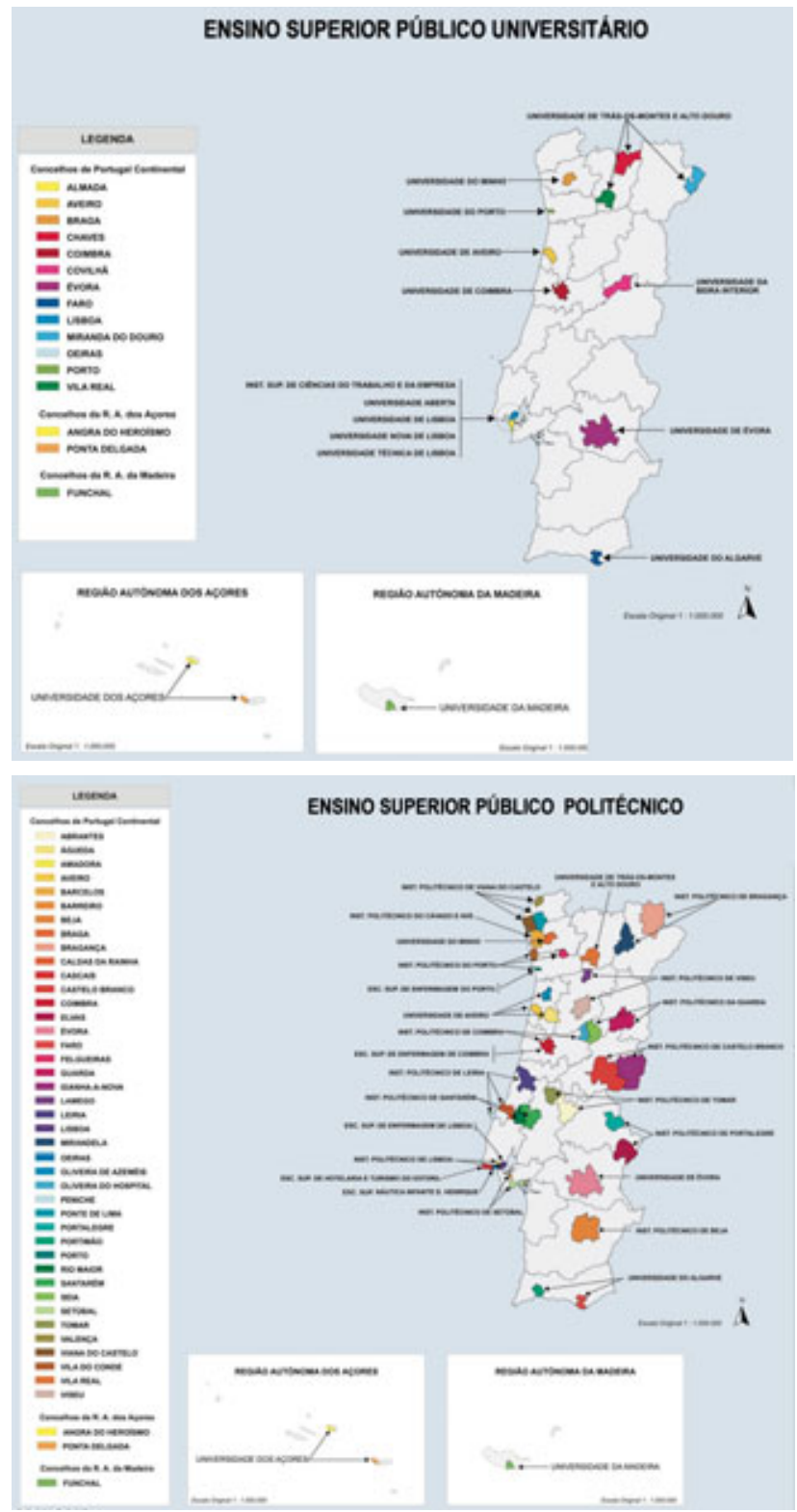

Fonte: DGES (2011/12) 
Também para a A3ESuma das vantagens do subsistema politécnico público, comparativamente ao universitário,enquadra-se precisamente na ampla cobertura geográfica da rede,sobretudo no que se refere ao interior do país (A3ES, 2012) (Figura 2).

Já ao nível da dispersão geográfica dos cursos de primeiro ciclo é de realçar que, com base em dados da DGES, relativos a 2011, consta-se que cerca de 30\% dos 4.689 cursos existentes estão concentrados em $3 \%$ do território nacional, mais concretamente no distrito de Lisboa. Quase metade destes, 4.689 cursos, encontram-se nos distritos de Lisboa e do Porto e concentrados em 5,6\% do território nacional. Manter o ensino superior nos três únicos distritos onde não existe mais nenhuma oferta de ensino superior representou em 2011, apenas 3,1\% do total do orçamento do ensino superior correspondente a 34.776.803,00€(Mourato, 2013b) (Figura 3).

Figura 3- Dispersão geográfica dos cursos de ensino superior

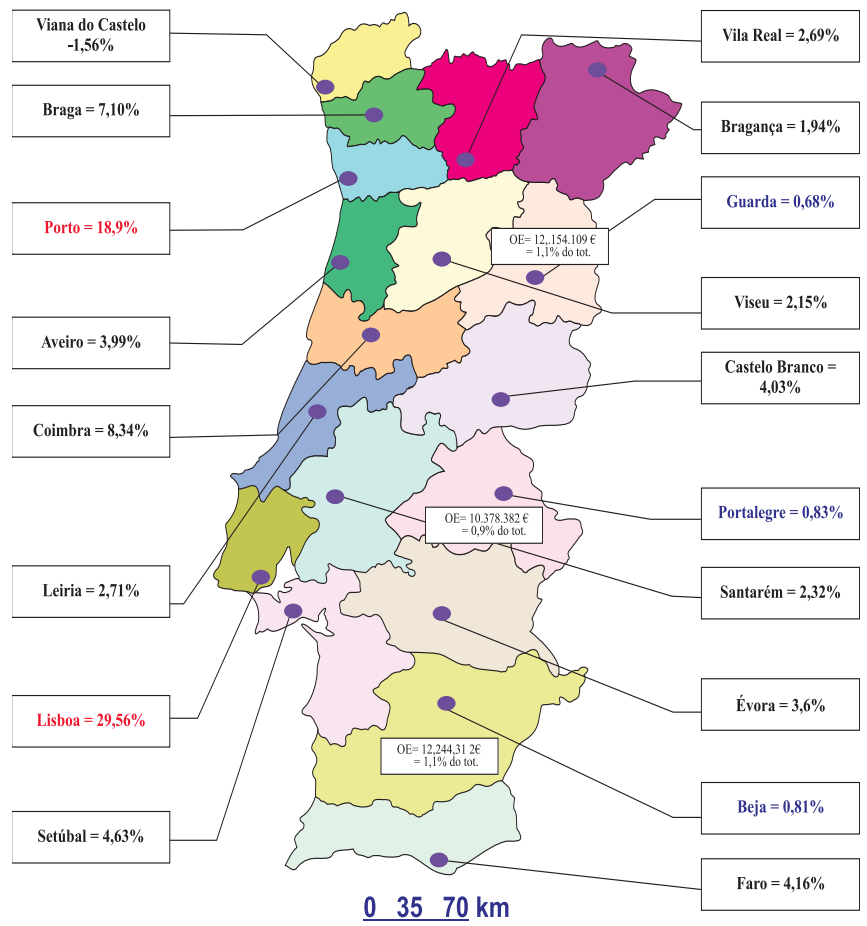

Fonte: DGES (2011) 
Também é de realçar o nível de competitividade que o ensino politécnico português alcançou nas últimas duas décadas. De facto, foi neste subsistema de ensino que se conquistouo maior acréscimo em termos de oferta ( $n^{\circ}$ de vagas).Além disso, tem-se igualmente assistido, não só a uma tendência na diminuição do fosso entre o volume de candidaturas a cada um dos subsistemas (universitário e politécnico), mas também a um decréscimo do peso relativo da procura preferencial pelo ensino universitário ${ }^{9}$, o que se deve ao facto de parte dessa procura se ter direcionado para o ensino politécnico (Urbano, 2011).

A evolução do número de alunos matriculados é outro indicador que, também, comprova a evolução positiva do segmento politécnico (Figura 4). Esta manifesta-se, assim, num indiciador de crescente reconhecimento pela sociedade da qualidade das formações ministradas no ensino politécnico (Urbano, 2008). De realçar que no ano letivo de 2011/12, estavam inscritos em instituições de ensino superior público 317.588 estudantes, 119.321 dos quais em instituições de ensino politécnico e 198.267 em instituições do subsistema universitário, representando por conseguinte o sector politécnico $38 \%$ da totalidade dos estudantes inscritos no ensino superior público, o que corresponde a $29 \%$ da totalidade do ensino superior (DGEEC $\left.{ }^{10}, 2012\right)$ - Figura 4.

Figura 4 - Evolução do ensino politécnico: 1995/96 - 2011/12

A. Evolução do número de vagas no ensino superior

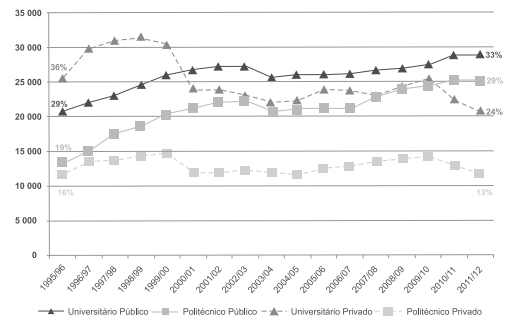

B. Evolução do número de inscritos no ensino superior*

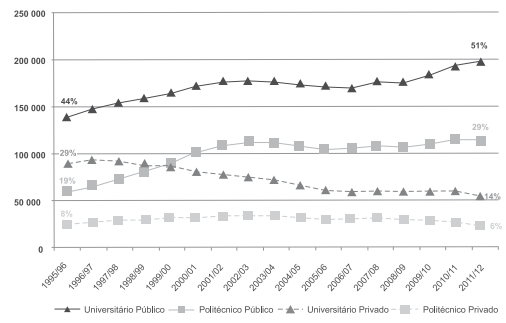

Fonte: CCISP, com base em dados disponibilizados pela Direção-Geral de Estatísticas da Educação e Ciência (DGEEC)

9 Tendo por referência os dados da $1^{a}$ fase do Concurso Nacional de Acesso ao Ensino Superior até 2010.

10 Direção-Geral de Estatísticas da Educação e Ciência 


\subsection{Impacto regional das instituições politécnicas}

No entender da Comissão Europeia, as instituições de ensino superior contribuem para o desenvolvimento regional, para a coesão económica, social e territorial de forma sustentável (Comissão Europeia, 2007). Também Vossensteyn (2012) enfatiza especificamente o contributo das instituições de ensino politécnico para o desenvolvimento regional, retratando estes estabelecimentos enquanto entidades de matriz marcadamente regional (tanto no que respeita à atração e recrutamento de estudantes, como à influência que exercem no mercado de trabalho da região, ou na colaboração com os parceiros sociais), tendo muitas vezes a função de estimular/apoiar a economia local - e.g. República Checa, Finlândia, Dinamarca, Noruega, Suíça e Irlanda (neste último país este tipo de instituições tem mesmo a missão de educar para a indústria e comércio locais).

Efetivamente, uma das intenções subjacentes à implementação do subsistema politécnico em Portugal foi, precisamente, a promoção do desenvolvimento regional e das relações com as atividades económicas e sociais. Esta política ainda vigora até àpresente data (Costa, 2002; Diogo, 2009). Este é o princípio para que a formação de cariz politécnico se destine não só a responder às necessidades sentidas a nível nacional, mas também às exigências específicas das regiões onde se encontram inseridas as instituições politécnicas. No mesmo contexto, a European University Association (EUA) destaca que um dos pontos fortes dos atuais institutos politécnicos, no sentido da sua diferenciação competitiva, corresponde à sua distribuição geográfica, com o consequente apoio à economia regional e local, designadamente, na relação privilegiada com as pequenas e médias empresas que constituem a maioria do tecido empresarial português (EUA, 2013).

O Índice Sintético de Desenvolvimento Regional é um indicador do Instituto Nacional de Estatística (INE) que fornece uma visão alargada do crescimento regional, através da sua estruturação em três componentes, nomeadamente: competitividade, coesão e qualidade ambiental. Atendendo a dados de 2008, este indicador refletia que apenas 3 das 30 sub-regiões de Portugal superavam a média nacional, a saber: Grande Lisboa, Pinhal Litoral e Minho-Lima. Já o Baixo Vouga e a Beira Interior Sul apresentavam um desempenho 
marginalmente abaixo da referência nacional. No que respeita à competitividade verificava-se um contraste entre o Litoral continental (com maior competitividade) e o Interior (INE, 2011) - Figura 5.

Figura 5 - Índice Sintético de Desenvolvimento Regional (2008)

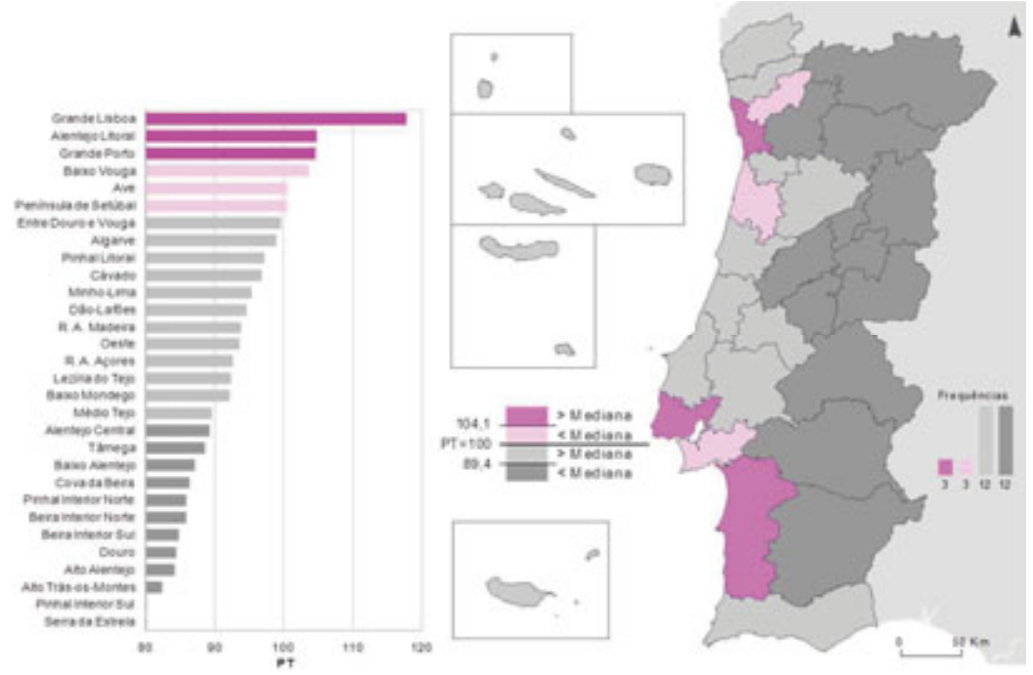

Fonte: INE (2011)

Ao nível da competitividade verifica-se, assim, um contraste entre o litoral continental, com maior competitividade, e o interior (Mourato, 2013b).

Já um estudorecente promovido pelo CCISP, no qual participaram sete institutos politécnicos, conclui que o impacto direto destas instituições nas respetivas regiões varia entre os 27 e 171 milhões de euros, sendo que o seu peso médio no PIB varia entre os $5 \%$ e os $11 \%$ da região onde estão inseridas e são responsáveis pelo emprego de mais de $12 \%$ da população ativa dos concelhos. Esta investigação concluiu igualmente que, por cada euro investido pelo Estado no financiamento destas instituições, existe um retorno médio de 4,22€, podendo atingir o máximo de 8,07€ (Alves et al., 2014).

O papel regional das UAS está em transformação, nomeadamente ao dar capacidade às regiões de serem atrativas a nível global e salientam-se cinco áreas em que as instituições politécnicas 
podem contribuir positivamente para o desenvolvimento regional (CHEPS, 2013):

- Estimulando a inovação.

- Facilitando clusters de empresas inovadoras.

- Fixandotalentos/recursos humanos qualificados.

- Desenvolvendo a cultura e a marca local.

- Promovendo o capital humano.

\subsection{Cooperação entre instituições politécnicas e as empresas}

Ao longo dos anos constatou-se uma evolução na Educação. Este conceito deixou de ser entendido como um fenómeno natural mas sobretudo como um fenómeno social. Logo, numa realidade em constante evolução as instituições de ensino devem acompanhar as transformações verificadas no meio envolvente, de modo a serem um lugar de aprendizagem e formação dos futuros profissionais. $\mathrm{O}$ empreendedorismo deve ser encarado como uma contribuição para o desenvolvimento da sociedade. As escolas para criarem valor têm de ser empreendedoras proporcionando um maior índice de qualidade de vida (Bucha, 2006). Esta mudança, é motivada, em parte, por uma alteração estratégica das empresas, na medida em que estas já não estão interessadas em desempenhar um papel tão direto na formação dos seus trabalhadores. No entanto, têm a necessidade de se munir do melhor quadro de pessoal para competirem a um nível global com menor custo de tempo e dinheiro. (CCISP, 2013a)

Para além da colaboração com as PME através da investigação baseada nas necessidades das empresas, as instituições politécnicas podem fomentar a «especialização regional inteligente» (identificando novas ligações tecnológicas e promovendo a inovação onde as PME possam não ter o know-how ou os recursos necessários para a implementar), através de duas vias (CHEPS, 2013): 
- Apoiar as empresas na melhoria da sua capacidade de inovação, e;

- Colaborar ativamente com parceiros locais (empresas e parceiros políticos) de modo a criar agendas comuns para o desenvolvimento estratégico regional.

Nesta missão enunciam-se algunsexemplos em concreto (Mourato, 2013c):

- O impactResOrgRisk - Avaliação do risco ambiental da utilização de resíduos orgânicos como corretivos do solo, do Instituto Politécnico de Beja.

- InovEnergy - Eficiência energética no sector agroindustrial, do Instituto Politécnicode Castelo Branco.

- Eletrodeposição de filmes de óxido do tipo espinela em substratos de aço inoxidável para o desenvolvimento de novos elétrodos para supercondutores, do Instituto Politécnico Setúbal.

- Desenvolvimento de novos condutores com condução por iões intersticiais para separação de oxigénio e conversão de hidrocarbonetos, do Instituto Politécnico Viana do Castelo.

- Centro de BioEnergia - Laboratório e incubadora de empresas de base tecnológica focada na área da Bioenergia, do Instituto PolitécnicoPortalegre.

Também é merecedor de realce o recente Protocolo celebrado, em junho do presente ano, entre as instituições politécnicas e o Grupo Águas de Portugal para reforçar as parcerias já existentes.

Concluindo este capítulo, a nova ordem económica centra-se no desenvolvimento de recentes conhecimentos e tecnologias.Alimentase destes para criar novos produtos de valor acrescentado, aumentando a produção e reduzindo os custos. Hoje é inquestionável que o tecido empresarial tem que recorrer a ferramentas e processos tecnicamente mais complexos,impulsionado a reconversãodo seu parque tecnológico. As tendências sugerem que o futuro irá reservar uma acentuação deste fenómeno (CCISP, 2013a). 
Esta missão caberá a todo o sistema de ensino superior português, embora que, pelo fruto da sua distribuição geográfica e da sua natureza, as IES politécnicas estão melhor posicionadas para apoiar as regiões e as empresas que nelas se situam (CCISP, 2013a).

\subsection{O exemplo do Poliempreende}

O Poliempreende é um concurso de ideias e projetos de vocação empresarial, no qual participam todos os membros do CCISP.O objetivo é estimular o empreendedorismo e proporcionar saídas profissionais através da criação do próprio emprego (Mourato, 2014).

O Poliempreende foi o vencedor nacional na categoria de Investimento em Competências Empreendedoras dos Prémios Europeus de Promoção Empresarial (2013), organizado em Portugal pelo IAPMEI.Em 9 edições do Poliempreende já resultaram (Mourato, 2104):

- 779 projetos, com a participação de 2483 alunos, a criação de 48 empresas (taxa de sobrevivência igual a $71 \%$ ) e o registo de 82 patentes.

- 3.047 alunos em oficinas de formação (E1, E2) e 200 formações em empreendedorismo.

- Mais de 100 professores beneficiários de formação específica.

- Estudos avaliativos do trabalho desenvolvido (Ex: o lançamento do livro "Empreendedorismo e Motivações Empresariais no Ensino Superior").

\subsection{Internacionalização}

Numa época global o estudo do fenómeno da internacionalização económica e empresarial de um país pequeno e aberto ao exterior como Portugal deve ser alvo de reflexão (Santos \& Ribeiro, 2005). Assim, uma outra vertente decisiva do ensino superior é a sua internacionalização e, em particular, sem prejuízo das suas caraterísticas próprias, a integração do sistema português na dimensão 
europeia (Simão, Santos \& Costa, 2002)

As instituições de ensino superior a nível mundial têm vindo a reforçar as suas atividades de internacionalização, sobretudo no que se refere ao recrutamento de estudantes a nível internacional. A internacionalização do staff das instituições e das suas atividades de investigação são aspetos que também têm vindo a ganhar importância (CHEPS, 2013). Conforme se referiu o papel regional das UAS está em transformação, nomeadamente ao dar capacidade às regiões de serem atrativas a nível global(CHEPS, 2013).

O ensino politécnico português acompanha esta tendência. Os programas de intercâmbio das instituições de ensino superior politécnico envolvem a mobilidade de estudantes, docentes e colaboradores entremais de 60 países, de entre os quais se destacam os seguintes indicadores (Mourato, 2013d):

Figura 6 - Mobilidade Internacional de Estudantes das Instituições Politécnicas

\begin{tabular}{|c|c|c|c|}
\hline Paises & $\begin{array}{c}\text { Estudantes } \\
\text { Recebidos } \\
\%\end{array}$ & Paises & $\begin{array}{c}\text { Estudantes } \\
\text { Enviados } \\
\%\end{array}$ \\
\hline Espanha & $24 \%$ & Espanha & $25 \%$ \\
\hline Polónia & $13 \%$ & Polónia & $18 \%$ \\
\hline Brasil & $7 \%$ & Rep. Checa & $6 \%$ \\
\hline Turquia & $6 \%$ & Itália & $6 \%$ \\
\hline Lituânia & $6 \%$ & Brasil & $5 \%$ \\
\hline Rep. Checa & $5 \%$ & Bélgica & $4 \%$ \\
\hline Itália & $5 \%$ & Lituânia & $4 \%$ \\
\hline Bélgica & $5 \%$ & Finlândia & $3 \%$ \\
\hline Roménia & $4 \%$ & Hungria & $3 \%$ \\
\hline Finlândia & $2 \%$ & Reino Unido & $3 \%$ \\
\hline
\end{tabular}

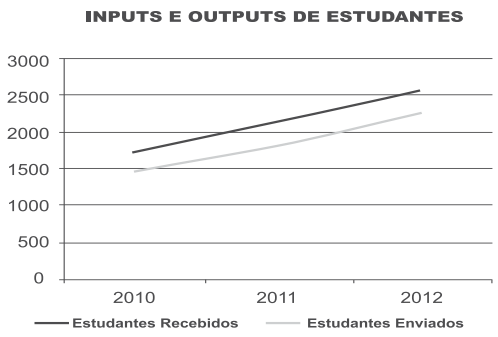

Fonte: CCISP 2013 
Figura 7 - Mobilidade Internacional de Docentes das Instituições Politécnicas

\begin{tabular}{|c|c|c|c|}
\hline Paises & $\begin{array}{c}\text { Estudantes } \\
\text { Recebidos } \\
\%\end{array}$ & Paises & $\begin{array}{c}\text { Estudantes } \\
\text { Enviados } \\
\%\end{array}$ \\
\hline Espanha & $20 \%$ & Espanha & $29 \%$ \\
\hline Polónia & $14 \%$ & Itália & $7 \%$ \\
\hline Brasil & $8 \%$ & Bélgica & $6 \%$ \\
\hline Turquia & $7 \%$ & Finlândia & $6 \%$ \\
\hline Lituânia & $6 \%$ & Polónia & $5 \%$ \\
\hline Rep. Checa & $4 \%$ & Turquia & $5 \%$ \\
\hline Itália & $4 \%$ & França & $3 \%$ \\
\hline Bélgica & $3 \%$ & Lituânia & $3 \%$ \\
\hline Roménia & $3 \%$ & Hungria & $3 \%$ \\
\hline Finlândia & $3 \%$ & Rep. Checa & $3 \%$ \\
\hline
\end{tabular}

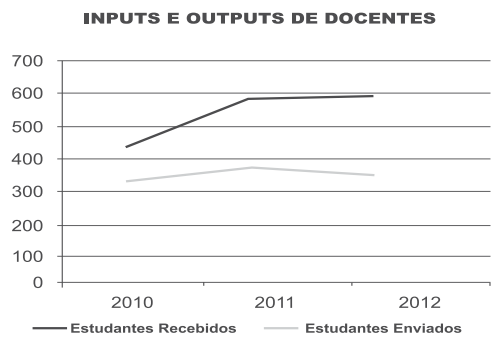

Fonte: CCISP 2013

Figura 8 - Mobilidade Internacional de Colaboradores das instituições Politécnicas

RANKING DOS 10 PRINCIPAIS PAÍSES

\begin{tabular}{|l|c|l|c|}
\hline \multicolumn{1}{|c|}{ Paises } & $\begin{array}{c}\text { Estudantes } \\
\text { Recebidos } \\
\%\end{array}$ & \multicolumn{1}{|c|}{ Paises } & $\begin{array}{c}\text { Estudantes } \\
\text { Enviados } \\
\%\end{array}$ \\
\hline Polônia & $27 \%$ & Espanha & $31 \%$ \\
\hline Espanha & $17 \%$ & Itália & $7 \%$ \\
\hline Lituânia & $8 \%$ & Finlândia & $7 \%$ \\
\hline Turquia & $8 \%$ & França & $5 \%$ \\
\hline Rep. Checa & $6 \%$ & Bélgica & $4 \%$ \\
\hline Bélgica & $3 \%$ & Holanda & $4 \%$ \\
\hline Alemanhã & $3 \%$ & Hungria & $4 \%$ \\
\hline Finlândia & $3 \%$ & Reino Unido & $4 \%$ \\
\hline Itália & $2 \%$ & Polónia & $4 \%$ \\
\hline Eslovénia & $2 \%$ & Rep. Checa & $4 \%$ \\
\hline
\end{tabular}

INPUTS E OUTPUTS DE COLABORADORES

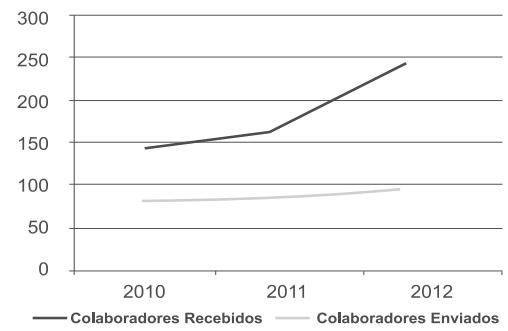

Fonte: CCISP 2013

Também é de manifesta pertinência realçar que as instituições politécnicas portuguesas participam em cerca de 200 projetos de investigação/cooperação internacional e que estes envolvem (Mourato, 2013d):

- Uma média de participação de nove instituições por projeto.

- Um valor total que ascende aos $146.336 .920,87 €$.

São, igualmente, ministrados diversos programas (desde o $1^{0}$ ao $3^{\text {o }}$ ciclo, incluindo cursos de pós-graduação) em 20 áreas distintas do conhecimento e que envolvem a parceira com inúmeras instituições de elevado prestígio internacional (Mourato, 2013d). 


\section{O RJIES ${ }^{11}$ : a sua última proposta de revisão, o parecer do CCISP e respetivas sugestões ${ }^{12}$}

Perante a proposta de alteração à Lei N.. 62/2007, de 10 de setembro, a qual estabelece o RJIES foi o CCISP convidado, pela tutela, a emitir um parecersobre a temática. Este documento foi expedido a 2 de agosto de 2013 e na generalidade o Conselho Coordenadormanifestou o seu desacordo com alguns aspetos da proposta, na qual perpassava, de uma maneira geral, a consagração de um regime de menorização do ensino politécnico dentro do sistema binário de ensino superior, perdendo-se ainda a oportunidade de devolver a autonomia às instituições para que estas pudessem desenvolver em pleno a sua missão. Dos aspetos negativos foram destacados (CCISP, 2013b):

- A impossibilidade dos Institutos Politécnicos poderem aceder ao regime de autonomia reforçada, quando até então não lhes era vedado o acesso ao regime fundacional.

- As instituições de ensino politécnico ficarem obrigadas aos limites de contratação previstos, enquanto as instituições de ensino universitário são isentas do seu cumprimento.

- Ser alterada a composição do corpo docente traduzindo-se num menor grau de exigência e rigor, com graves consequências para as instituições, na medida em que colide com os processos de avaliação dos cursos e, igualmente, com os normativos constantes do Estatuto da Carreira do Pessoal Docente do Ensino Superior Politécnico (ECPDESP), designadamente os que obrigam a que pelo menos $70 \%$ do corpo docente seja constituído por professores de carreira.

- Ser revogadoo regime jurídico do título de especialista, sem se fundamentar em qualquer avaliação do percurso feito pelas Instituições e docentes até ao

11 Regime Jurídico das Instituições de Ensino Superior.

12 Este capítulo irá fundamentar-se, integralmente, no Parecer emitido pelo CCISP (CCISP, 2013b), a 2 de agosto de 2013, por solicitação da Secretaria de Estado do

Ensino Superior, sobre a proposta de alteração da LEI N.․ 62/2007 que estabelece o Regime Jurídico das Instituições de Ensino Superior. 
momento e sem ter em atenção o período transitório previsto no ECPDESP, que valoriza o título de especialista para a integração na carreira.

- Os prazos para deferimento tácito sejam diferentes e menores para as IES privadas em relação às públicas, assim como a delimitação regional que se pretende dar às IES politécnicas.

O CCISP considera que estes aspetos acima referenciados acesso a autonomia reforçada, discriminação ao nível dos limites à contratação de pessoal, composição do corpo docente e o regime de acesso ao conceito de especialista - constituem propostas inaceitáveis dentro de uma lógica de valorização crescente que se pretende para o ensino superior politécnico (CCISP, 2013b).

Além destes aspetos, outros háque mereceram o acordo do Conselho atendendo à sua pertinência, nomeadamente (CCISP, 2013b):

- As alterações produzidas para regular as competências, deveres, prazos e direitos tanto do provedor do estudante como do fiscal único.

- A tramitação proposta para os Serviços de Ação Social, a qual dá maior latitude às instituições para poderem partilhar os seus serviços com outras instituições, possibilitando assim a racionalização de serviços e a poupança de recursos, o que contribuirá para o esforço nacional.

- Apossibilidade consagrada dos imóveis do domínio privado do Estado poderem vir a ser transferidos para o património das instituições. Contudo, o Conselho Coordenador não deixou de manifestar o seu desacordo com a discriminação negativa que é imposta às instituições politécnicas ao possibilitar-se a incorporação no património do Estado de imóveis pertencentes às instituições, situação que, além de discriminatória, viola a autonomia patrimonial das instituições.

O CCISP aproveitoupara reiterar algumas propostas já apresentadas das quais se salientam:a necessidade e oportunidade de assinalar aspetos essenciais às legítimas pretensões das Instituições 
Politécnicas nomeadamente no que diz respeito ao acesso às formações de terceiro ciclo e à possibilidade de utilizaremoutra designação, especialmente num contexto de internacionalização, bem como a clarificação de atuais normas relativas às competências e gestão dos órgãos, estratégicas até pelos aspetos de responsabilidade financeira que envolvem (CCISP, 2013b).

Porém, tal como o próprio RJIES estipula mostra-se necessária uma avaliação global antes de se proceder a qualquer revisão.

\section{Caminhos para o futuro}

Projetar o futuro é uma tarefa complexa e incerta. São elevados os riscos para quemambiciona desempenhar essaingratamissão. Existem imensas variáveis que o agente terá que ter em conta para desenvolver, bem como a incumbência de avistar, com algum rigor, o que o futuro pode trazer. Mesmo que se obedeçam a todos estes raciocínios de forma zelosa, não existem garantias de que a previsão formulada se venha a realizar. (CCISP, 2013a)

A missão e as funções das instituições de ensino superior devem constar de programas estratégicos, onde sejam esclarecidas as suas atividades e englobem, de forma coerente, as diversas unidades orgânicas. Estes planos deverão elucidar objetivos, metas,indicadores setoriais e globais. Deverão ser aplicadas as técnicas de benchmarking no sentido de melhor aferir a excelência e a qualidade. Estes programas representarãoinstrumentos essenciais orientadores da vida académica, cultural e científica, bem como da inserção institucional ao nível regional, nacional e internacional (Simão, 2003).

A preservação e dignificação do ensino politécnico português são eixos estratégicos prioritários para o CCISP. Em resultado de uma reflexão realizada, ao longo dos últimos dois anos,concluíram-se um conjunto de propostas. Estas tiveram em consideração diversos estudos e experiências disponíveis. Sobretudo, visam mormente clarificar e reforçar o papel das instituições politécnicas públicas no sistema de ensino superior português (CCISP, 2013c).

A matriz das propostas apresentadas pelo CCISP assentaem cinco pilares fundamentais de consolidação do subsistema, articulando as principais orientações do quadro de referência europeu 
com as necessidades do país e do sistema, a saber (CCISP, 2013c):

- Otimização de recursos e da capacidade instalada.

- Aumento da qualificação dos recursos humanos do País, com particular destaque para a formação ao longo da vida e para a existência de novos públicos.

- Melhoria da qualidade de ensino, consolidando um modelo formativo de orientação profissionalizante.

- Desenvolvimento da investigação aplicada como catalisadora da atividade económica, da inovação e da criação de riqueza, e promotora do desenvolvimento e da coesão regional, para além de fonte complementar de financiamento das instituições.

- Internacionalização como estratégia de abertura ao exterior e de enriquecimento técnico-científico e cultural, aumentando, simultaneamente, os recursos próprios das instituições e a captação de investimento externo.

Com referência a estas bases o CCISP tem como pertinentes os seguintes eixos orientadores para a reorganização do ensino superior em Portugal, designadamente (CCISP, 2013c):

Sintonia das instituições politécnicas com as suas homólogas europeias, adotando a designação, em termos internacionais, deUniversityofAppliedSciences.

Reordenação da rede de instituições politécnicas, no respeito pela sua autonomia e por sua iniciativa, através de consórcios ou de fusões que resultem de um projeto com evidentes mais-valias para o sistema de ensino superior português e para o País.

Consolidação da identidade dos dois subsistemas de ensino superior.

Racionalização do número de cursos de 1.ํㅜㄹ ciclo, incluindo a harmonização das designações, em todo o ensino superior.

Otimização dos recursos financeiros, mantendo o subsistema sustentável. 
Reforço da investigação aplicada, da criação cultural e da prestação de serviços especializados, e transferência de conhecimentos para a comunidade, com particular incidência na promoção da inovação regional.

Reforço da internacionalização, com ligação, nomeadamente, à comunidade lusófona e à Europa.

Credibilização e promoção de uma via de qualificação e especialização profissionalizante, com títulos e graus académicos desde os ciclos curtos (shortcycles) até ao doutoramento de caráter profissional.

É ainda de realçar que para a sustentabilidade do ensino superior em Portugal, o CCISP apresentou as seguintes propostas (CCISP, 2013c):

- Implementação de uma política de vagas equilibrada com o número de candidatos ao ensino superior e estável entre os subsistemas.

- Definição de um catálogo de ciclos de estudos, dos diversos níveis, assente num modelo formativo diferenciado, para cada perfil institucional, com estabelecimento de um período de transição.

- Integração no ensino superior dos Cursos de Especialização Tecnológica ou criação dos Cursos Superiores Especializados, com duração de dois anos ( $S h$ ortCyclesofHigherEducation $)^{13}$.

- Criação de Centros de Investigação Aplicada, transversais a todo o sistema de ensino superior politécnico, e em articulação com o tecido empresarial, com programa próprio de financiamento na FCT.

13 À data da conclusão deste documento encontrava-se em discussão a proposta de alteração legislativa, por parte da tutela, no que concerne ao facto do ensino politécnico passar a conferir o Diploma Superior de Estudos Especializados, bem como os CET ministrados por instituições de ensino superior cessarem a sua ministração até 31 de Dezembro de 2015. 


\section{Considerações finais}

A situação narrada permitemeditaro futuro com esperança. $\mathrm{O}$ ensino superior politécnico é vital para o desenvolvimento do país e deve aprofundar-se a sua missão institucional, a sua especificidade e a sua ligação ao mercado de trabalho (FNAEESP, 2003).No futuro será determinante que o ensino superior seja preferentemente global e acessível, capaz de entender e desenvolver novos paradigmas, pronto a responder aos desafios do mundo e, simultaneamente, provocador em relação ao preconcebido e ao instalado. Um ensino superior das pessoas e para as pessoas, fonte de satisfação e crescimento individual e coletivo.Almeja-se que o ensino superior português evolua nesse sentido, visto que não há outra opção possível para uma sociedade que se quer de primeiro mundo (CCISP, 2013a)

Longínquossão os tempos em que ter formação superior era sinónimo, só por si, de obtenção de bons salários e carreiras promissoras. No futuro que agora se esboça, ter uma qualificação académica será apenas uma das componentes necessárias para possibilitar o acesso a uma profissão. Uma qualificação académica superior passou de determinante para a obtenção de um bom salário a essencial para entrar no mercado de trabalho. Assim, entende-se que as instituições de ensino superior terão um papel mais relevante na vida dos cidadãos, pois a nova economia irá ditar que estes se apresentem no mercado de trabalho mais bem preparados, quer do ponto de vista científico, quer ao nível das competências adquiridas. Como tal, considera-se que esta carência irá ter um impacto positivo nos ingressos no ensino superior, já que a procura por uma formação superior será tendencialmente maior. (CCISP, 2013a).

É consabido queo País continua a ter um enorme défice de qualificação,sendo necessário um ensino superior mais vocacionado e profissionalizante. Para efetivar esta questão entende-se que deverão ser viabilizadas as condições para a consolidação de um sistema binário coerente, diversificado e sustentado. Assim, torna-se necessária a definição de cada um dos subsistemas, reforçando a matriz profissionalizante do ensino politécnico com um modelo de formação e investigação orientado para a atividade empresarial ou criativa, de impacto direto no tecido produtivo (Mourato, 2013a).

Para esta meta, a estratégia nacional para o ensino superior deve 
radicar na defesa de um sistema forte, articulado e responsável face aos grandes objetivos do País, procurando a competitividade e a capacidade de afirmação internacional (Mourato, 2013a). Os critérios de racionalidade económica, eficiência e eficácia terão que ser tidos em conta paraque se alcance a máxima rentabilidade dos recursos públicos. Para isso, as instituições devem equacionar desenvolver parcerias e consórcios no sentido de realizarem atividades conjuntas, sem que seja posto em causa o seu perfil individual. Ressaltam exemplos como a implementação da Associação de Politécnicos do Centro e da Associação de Politécnicos do Norte que se traduzem em parcerias resultantes dos politécnicos dessas regiões. São ainda de realçar, apesar da autonomia das instituições, os projetos resultantes da cooperação conjunta em que o CCISP surge como entidade coordenadora, tais como, o e-Politécnico, ou o Poliempreende, bem como outras iniciativas comuns, nomeadamente, a atribuição de graus, a internacionalização, os centros de investigação aplicada e a prestação de serviços à comunidade (Mourato, 2013a).

Vendo o futuro com algum otimismo, espera-se que as instituições sejam avaliadas pela sua qualidade e não pelo seu enquadramento no sistema de ensino superior português e que este não esteja ainda amarrado às orientações políticas ciclicamente diferentes (e algumas vezes opostas). No futuro, as instituições não poderão viver envoltas no turbilhão da burocracia, que lhes retira autonomia e liberdade de ação. Não podem depender do financiamento de curto prazo, sistematicamente interrompido e criador de dificuldades na resposta das instituições aos projetos plurianuais. Não podem ser discriminatórias e inacessíveis para uma parte importante da população, pois o ensino superior terá que ser mais democrático e menos elitista, a bem da economia do país. Julga-se que somente com uma implementação de instituições públicas de ensino superior em todo o território nacional é que será viável seguir estratégias cujo foco principal reside na qualificação dos quadros de trabalhadores, fator que será essencial à criação de emprego e de riqueza (CCISP, 2013a).

Numa economia baseada no conhecimento é essencial que o ensino superior português se posicione entre os melhores e urge continuar a apostar na qualificação do corpo docente, tal como aumentar o nível e a capacidade da investigação.Igualmente, manifesta-se de elevada pertinência abraçar a internacionalização 
das instituições, aproveitando os laços criados com cidadãos deste mundo por uma língua comum (Mourato, 2013a).Não esqueçamos que a Língua Portuguesa tem um passado de reconhecido valor, um presente consolidado e tudo aponta para uma tendência futura no mesmo sentido (Silva, 2004).

Importa, ainda, dar continuidade ao processo de acreditação da oferta formativa e das instituições de forma rigorosa, com um processo cada vez mais exigente, segundo padrões europeus e mundiais. A transparência deste processo e a divulgação dos seus resultados contribuem para a credibilização e reconhecimento do sistema de ensino superior português. É indesmentível que instituições têm sabido transformar-se e estão hoje dotadas de melhores recursos. A internacionalização na docência e na investigação são fatores que em muito têm contribuído para a evolução das instituições. Há, pois, que continuar a apostar nesta estratégia (Mourato, 2013d).

As sociedades mais desenvolvidas investem intensivamente no ensino superior. Dotar as instituições dos recursos necessários ao seu funcionamento, promover a investigação e apoiar os estudantes são condições básicas para o desenvolvimento do ensino superior e do país (CCISP, 2013a).

Por último, aprofundar o sistema binário, dando liberdade a cada instituição para definir o seu projeto estratégico e identitário, é um bom itinerário para o ensino superior português. $\mathrm{O}$ ensino superior será tanto mais forte quanto maior diversidade existir nas missões das instituições. Assim, serão desenvolvidas vias alternativas e complementares, igualmente dignas, proporcionando aos estudantes a sua integração em ambientes ajustados aos seus perfis, gerando oportunidades para todos(CCISP, 2013a). 


\section{Referências Bibliográficas}

ADISPOR (2012). Espaço Europeu de Ensino Superior: Programas de estudo universitários de cariz politécnico. Estudo inédito, Centro de Estudos de Política Educativa, Lisboa, Portugal.

A3ES (2012). O sistema de ensino superior em Portugal - Parte I. Recuperado em 21 março, 2013, através de http://www.fenprof.pt/Download/FENPROF/ SM_Doc/Mid_132/Doc_6444/Anexos/SESP_Parte_I.pdf

Almeida, L. (2011). O sistema de ensino superior português: Expansão e desregulação. Reforma no quadro do Espaço Europeu de Ensino Superior. Porto: Media XXI.

Amorim, J.B.P.(2004). Estruturas Político-Económicas:QueCaminhos?Discurso do Presidente do Instituto Politécnico de Tomar na Sessão de Abertura Solene das Aulas em Novembro de 2004.Tomar. Instituto Politécnico de Tomar.

Alves, J., Carvalho, L., Carvalho, R. Correia, F., Cunha, J., Farinha, L., Fernandes, J., Ferreira, M., Lucas, E., Mourato, J., Nicolau, A., Nunes, S., Nunes, S., Oliveira, P., Pereira, C., Pinto, S., \& Silva, J. M. (2014).O Impacto Dos Institutos Politécnicos na Economia Local. Uma Primeira Reflexão. Lisboa: Conselho Coordenador dos Institutos Superiores Politécnicos.

Bucha, A. I. (2006). O Empreendedorismo Através da Escola, Revista de Ciências Empresariais e Jurídicas.Porto: Instituto Superior de Contabilidade e Administração do Porto.

Cardoso, S., Carvalho, T., \& Santiago, R. (2011). From students to consumers: Reflections on marketization of portuguese higher education. European Journal of Education, 46(2), 271-284

CCISP (2003). Parecer do CCISP. Avaliação, Revisão e Consolidação da Legislação do Ensino Superior, Coordenação Alberto Amaral. Lisboa: Fundação das Universidades Portuguesas.

CCISP (2006). Breve caracterização do ensino superior em Portugal: Visão dos Institutos Politécnicos. Lisboa: Autor.

CCISP (2013a). Uma Perspetiva Sobre o Ensino Superior em 2050.Estudo Inédito. Lisboa: Autor

CCISP (2103b). Parecer Sobre a Proposta de Alteração da Lei N. ${ }^{\circ}$ 62/2007, de 10 de setembro, que Estabelece o regime Jurídico das Instituições de Ensino Superior. Lisboa: Autor. 
CCISP (2013 c). Propostas Para o Futuro do Ensino Superior Politécnico Português.Lisboa: Autor

CHEPS (2013). Policy challenges for the Portuguese polytechnic sector: A report for the Portuguese Polytechnics Coordinating Council (CCISP). Lisboa: Conselho Coordenador dos Institutos Superiores Politécnicos.

Comissão Europeia (2007). Organização do sistema educativo em Portugal (2006/07). Recuperado a 6 Novembro, 2011, através de http://eacea. ec.europa.eu/education/eurydice/documents/eurybase/eurybase_full_reports/PT_PT.pdf

ComissãoEuropeia (2012). The European Higher Education Area in 2012: Bologna Process implementation report. Bruxelas, Bélgica: Education, Audiovisual and Culture Executive Agency.

Costa, J. V. (2002). Ensino universitário e politécnico. Recuperado a 15 Março, 2013, através de http://www.spbs.pt/ENSINO-UNIVERSITARIO-EPOLITECNICO.pdf

DGEEC (2012). Docentes por subsistema de ensino e habilitação académica, de 2001/02 a 2011/12. Recuperado a 15 Março, 2013, através de http://www. dgeec.mec.pt/np4/93/

DGES (2011/12). Rede pública do ensino superior. Recuperado a 16 Março, 2013, através de http://www.dges.mctes.pt/DGES/pt/Estudantes/Rede/ Ensino+Superior/Estabelecimentos/Rede+Pública/

DGES (n.d.). Informação sobre o sistema de ensino superior português. Recuperado a 16 Março, 2013, através de http://www.dges.mctes.pt/DGES/pt/ Reconhecimento/NARICENIC/Ensino+Superior/Sistema+de+Ensino+Sup erior+Português/

Diogo, S. M. A. (2009). A herança de Bolonha no sistema binário de ensino superior português. Dissertação de mestrado, Universidade de Aveiro, Aveiro, Portugal.

EUA (2013). Portuguese higher education: A view from the outside. Recuperado a 23 julho, 2013, através de http://www.eua.be/Libraries/Publication/ CRUP_final_pdf.sflb.ashx

File, J. (2013). Policy challenges for the Portuguese polytechnic sector.Recuperado a 29 Abril, 2013, através de http://www.ccisp.pt/Doc/CNE/CCISP\%20 workshop $\% 202 \% 20$ presentation.pdf 
FNAEESP (2003). Avaliação, Revisão e Consolidação da Legislação do Ensino Superior, Coordenação Alberto Amaral. Lisboa: Fundação das Universidades Portuguesas.

Harvey, L. (2004-13). Analytic Quality Glossary. Quality Research International. Recuperado a 15 Março, 2013, através de http://www.qualityresearchinternational.com/glossary/binarysystem.htm

Haug, G. \&Tauch, C. (2001). Learning structures and higher education systems in Central, Eastern and South Eastern Europe, Cyprus, Malta and Switzerland. EmEUA trends and learning structures in higher education reports series: Trends in learning structures in higher education (Trends II - Part III). Recuperado a 15 Março, 2013, através de http://www.aic.lv/ace/ace_disk/ acebook/Trends_all.pdf

Heckmann, C. (2012). Education at a Glance: OECD Indicators 2012 (Country note-Portugal). Recuperado a29 Março, 2013, através de http://www.oecd. org/education/CN\%20-\%20Portugal.pdf

INE (2011). Índice Sintético de Desenvolvimento Regional - 2008. Recuperado a 29 março, 2013, através de http://www.ine.pt/xportal/ xmain? $x$ pid=INE\&xpgid=ine_destaques\&DESTAQUESdest_boui=106837 721\&DESTAQUESmodo=2\&xlang=pt

Kirstein, J. (1999). Information on learning structures in higher education in the EU/EEA countries. EmEUA trends and learning structures in higher education reports series: Trends in learning structures in higher education (Trends I - Part II). Recuperado a 15 Março, 2013, através de http://www.aic.lv/ace/ ace_disk/acebook/Trends_all.pdf.

Lourtie, P. (2013). Rede de Ensino Superior em Portugal. Redes de Ensino Superior: Contributos Perante os Desafios do Desenvolvimento.Évora: Centro de Estudos e Formação Avançada em Gestão e Economia.

Machado, M. L., \& Taylor, J. S. (2010). The struggle for strategic planning in european higher education: The case of Portugal. Research in Higher Education Journal, 6, 1-20.

Mourato, J. (2013a). A Rede de Ensino Superior em Portugal: Perspetiva Institucional. Redes de Ensino Superior: Contributos Perante os Desafios do Desenvolvimento. Évora: Centro de Estudos e Formação Avançada em Gestão e Economia. 
Mourato, J (2013b). Educação e Ensino Superior no Interior. Comunicação apresentada no Congresso do Ensino Superior do Interior. 14-15 de novembro de 2013: Instituto Superior Politécnico de Bragança.

Mourato, J (2013c). Ensino Superior:Que Papel no Novo Contexto Económico. Comunicação apresentada no $23^{\circ}$ Congresso das Comunicações. 13 novembro de 2013; Centro de Congressos de Lisboa.

Mourato, J (2013d). Ensino Politécnico e a Internacionalização. Comunicação apresentada naConferência da Direção Geral de Ensino Superior: Internacionalização do Ensino Superior. 14 de Novembro de 2013: Teatro Thalia, Lisboa.

Mourato, J. (2014). Vagas de Cursos e Taxas de Empregabilidade: Que Correlação? Que Condicionamentos? Que Métricas Alternativas?Comunicação apresentada no $3^{\circ}$ Encontro Nacional de Gabinetes de Saídas Profissionais. 14 de janeiro de 2014: Universidade de Coimbra.

OCDE (2006). Revisões das Politicas Nacionais para a Educação - Ensino Terciário em Portugal - Relatório de Observadores.Recuperado a em 10 de julho de 20014 em: http://www.gep.msess.gov.pt/edicoes/revistasociedade/r31_6.pdf

Santos, J. F., \& Ribeiro, J. C. (2005). Processo de Abertura e Internacionalização da Economia Portuguesa: Balanço e Perspectivas Futuras: Revista de Ciências Empresariais e Jurídicas, Porto, Instituto Superior de Contabilidade e Administração do Porto.

Seixas, A. M., \& Costa, R. J. (2003, Abril). Ensino superior deve abrir-se a novos públicos. A Página da Educação, 122. Recuperado a 21 Março, 2013, através de http://www.apagina.pt/?aba=7\&cat=122\&doc=9403\&mid=2

Silva, L. M. (2004). O Português, Língua de Futuro (do Ocidente ao Oriente), Revista Internacional de Língua Portuguesa, II Ed. N. 3. Lisboa: Associação das Universidades de Língua Portuguesa.

Simão, J. V., Santos, S. M., \& Costa, A. A. (2002). Ensino superior: Uma visão para a próxima década. Lisboa: Gradiva.

Simão, J. V. (2003). Modernização do Ensino Superior da Ruptura à Excelência. Lisboa: Fundação das UniversidadesPortuguesas.

Teichler, U. (1988). Changing patterns of higher education systems. The experience of three decades. Londres, ReinoUnido: Jessica Kingsley. 
Teichler, U. (2004). Changing structures of the higher education systems: The increasing complexity of underlying forces. Em UNESCO (Ed.), UNESCO Forum Occasional Paper Series - Paper No. 6: Diversification of Higher Education and the Changing Role of Knowledge and Research (pp. 2-15). Recuperado a15 Março, 2013, através de http://unesdoc.unesco.org/ images/0014/001467/146736e.pdf

Teichler, U. (2008). The end of alternatives to universities or new opportunities? Em J. S. Taylor, J. B. Ferreira, M. De Lourdes Machado \& R. Santiago (Eds.), Non-University Higher Education in Europe (pp. 1-14). Dordrecht, Holanda: Springer.

Teixeira, R. A. M. (2010). Satisfação e lealdade dos alunos dos institutos politécnicos: O caso de Portugal. Trabalho de investigação, Universidad de Extremadura, Badajoz, Espanha.

Urbano, C. (2008, junho). O Ensino Politécnico - (Re)definição e (re)posicionamento no panorama da formação superior em Portugal. Comunicação apresentada no VI Congresso Português de Sociologia - Mundos Sociais: Saberes e Práticas, Lisboa, Portugal.

Urbano, C. (2011). A (Id)entidade do ensino superior politécnico em Portugal - Da Lei de Bases do Sistema Educativo à Declaração de Bolonha. Sociologia, Problemas e Práticas, 66, 95-115.

Vossensteyn, H. (2012). Characterisation of UAS institutions: International comparison $\mathcal{E}$ U-Map profiles. Comunicação apresentada na $2^{\text {nd }}$ Conference of Universisties of Applied Sciences Network (UASNET), Outubro. Bragança, Portugal. 